Published in final edited form as:

J Safety Res. 2016 September ; 58: 99-103. doi:10.1016/j.jsr.2016.05.001.

\title{
The direct costs of fatal and non-fatal falls among older adults - United States
}

\author{
Elizabeth R. Burns ${ }^{\star}$, Judy A. Stevens, Robin Lee \\ National Center for Injury Prevention and Control, Centers for Disease Control and Prevention, \\ Atlanta, GA, USA
}

\section{Abstract}

Introduction: This study sought to estimate the incidence, average cost, and total direct medical costs for fatal and non-fatal fall injuries in hospital, ED, and out-patient settings among U.S. adults aged 65 or older in 2012, by sex and age group and to report total direct medical costs for falls inflated to 2015 dollars.

Method: Incidence data came from the 2012 National Vital Statistics System, 2012 Healthcare Cost and Utilization Project-Nationwide Inpatient Sample, 2012 Health Care Utilization Program National Emergency Department Sample, and 2007 Medical Expenditure Panel Survey. Costs for fatal falls were derived from the Centers for Disease Control and Prevention's Web-based Injury Statistics Query and Reporting System; costs for non-fatal falls were based on claims from the 1998/1999 Medicare fee-for-service 5\% Standard Analytical Files. Costs were inflated to 2015 estimates using the health care component of the Personal Consumption Expenditure index.

Results: In 2012, there were 24,190 fatal and 3.2 million medically treated non-fatal fall related injuries. Direct medical costs totaled $\$ 616.5$ million for fatal and $\$ 30.3$ billion for non-fatal injuries in 2012 and rose to $\$ 637.5$ million and $\$ 31.3$ billion, respectively, in 2015 . Fall incidence as well as total cost increased with age and were higher among women.

Conclusion: Medically treated falls among older adults, especially among older women, are associated with substantial economic costs.

Practical application: Widely implementing evidence-based interventions for fall prevention is essential to decrease the incidence and healthcare costs associated with these injuries.

\section{Keywords}

Fall; Older people; Costs; Hospital care; STEADI

\footnotetext{
The Journal of Safety Research has partnered with the Office of the Associate Director for Science, Division of Unintentional Injury Prevention in the National Center for Injury Prevention \& Control at the Centers for Disease Control and Prevention (CDC) in Atlanta, Georgia, USA, to briefly report on some of the latest findings in the research and practice community. This report is the 40th in a series of CDC articles.

*Corresponding author at: Centers for Disease Control and Prevention, National Center for Injury Prevention and Control, 4770 Buford Highway NE, Mailstop F-62, Atlanta, GA 30341, USA. ync7@cdc.gov (E.R. Burns).

Publisher's Disclaimer: Disclaimer

Publisher's Disclaimer: The findings and conclusions in this report are those of the authors and do not necessarily represent the official views of the Centers for Disease Control and Prevention.
} 


\section{Introduction}

Falls are the leading cause of both fatal and non-fatal injuries among people aged 65 and older (Centers for Disease Control and Prevention, 2005). The high incidence, long-term effects, and significant costs associated with fall related injuries (Hornbrook, Stevens, Wingfield, et al., 1994) present a significant burden to our health care system (Hodgson \& Cohen, 1999). As many as $20 \%$ of falls result in serious injuries that may require prolonged medical care including hospitalization and rehabilitative services (Alexander, Rivara, \& Wolf, 1992).

Numerous studies have calculated the cost of fall related injuries (Alexander et al., 1992; Stevens, Corso, Finkelstein, et al., 2006; Carroll, Slattum, \& Cox, 2005; Englander, Hodson, \& Terregrossa, 1996; Ellis \& Trent, 2001; Roudsari, Ebel, Corso, et al., 2005; ShumwayCook, Ciol, Hoffman, et al., 2009; Finkelstein, Chen, Miller, et al., 2005; Rizzo, Friedkin, Williams, et al., 1998; Mahoney, Glysch, Guilfoyle, et al., 2005; Bohl, Fishman, Ciol, et al., 2010). The incidence and costs of fatal and non-fatal falls by treatment setting, sex, and age were reported in 2006 by Stevens et al (Stevens et al., 2006). They reported that $63 \%$ of fall related costs were for hospitalizations, $21 \%$ were for emergency department (ED) visits and $16 \%$ were for outpatient visits. They also found that total costs for women at every treatment setting were higher. Cost estimates, from Stevens et al., have been used widely to report the total costs of falls but did not report average costs of falls by treatment setting, sex, or age group. Additionally they have not been adjusted for the increases in the senior population.

The number of Americans over the age of 65 is increasing. In 2000, one in eight Americans was aged 65 or older, by 2013 this proportion had grown to one in seven, and by 2050 that proportion will grow to one in every five or an estimated 84 million older adults (Wiener \& Tilly, 2002). This study updates the estimates calculated by Stevens et al (Stevens et al., 2006). by adjusting for inflation and the aging U.S. population. Specifically we estimate the costs of fatal and non-fatal falls among persons aged 65 years and older using updated incidence data to calculate average and overall costs stratified by treatment setting (hospitalizations, ED visits, office-based and outpatient visits), sex, and age group.

\section{Methods}

The incidence of falls was calculated using multiple data sources because no single data set included fatal falls, hospitalizations, emergency department visits, hospital outpatient visits, and office-based visits. All analyses were limited to adults aged 65 years and older. Sample weights were applied to generate nationally representative estimates.

\subsection{Fatal falls}

The incidence of fatal falls in 2012 was obtained using the Centers for Disease Control and Prevention's Web-based Injury Statistics Query and Reporting System (Centers for Disease Control and Prevention, 2005) (WISQARS). WISQARS uses data from the National Vital Statistics System (i.e., death certificates). The WISQARS system also estimates the costs of fatal falls by totaling the average cost per fall death by place of death (on-scene/at home, dead on arrival at a hospital, in a hospital ED, in a hospital after inpatient admission, in a 
nursing home [including skilled nursing facilities], in a hospice). Depending on the place of death, included payments are: cost of a coroner or medical examiner, transport, ED cost, hospitalization cost, nursing home costs and hospice costs. A detailed description of the methodology has been described previously (Lawrence, 2014). All fatal medical costs were computed for total costs stratified by sex and age group. To further estimate 2015 costs, we inflated the 2012 costs using the health care component of the personal consumption expenditures (PCE) price index (http://bea.gov/index.htm). PCE includes medical care services paid by employers through employer-provided health insurance and medical care services paid for by government programs like Medicaid and Medicare (McCully, Moyer, \& Stewart, 2007).

\subsection{Non-fatal falls}

To calculate the incidence and cost of non-fatal falls, we include data from hospitalizations, ED visits, and office-based and outpatient visits. For hospitalizations, we used the Healthcare Cost and Utilization Project-Nationwide Inpatient Sample (HCUP-NIS), which includes hospital discharge data from 44 states and covers over $95 \%$ of the U.S. population. The HCUP-NIS dataset does not distinguish between initial admissions and readmissions; therefore, some records may be for the same injury. We used HCUP's query system to determine readmission rates by initial diagnosis and adjusted incidence downward to account for readmissions. Records were excluded if they indicated that the patient had died during their hospitalization.

For ED visits, we used the HCUP-Nationwide Emergency Department Sample (NEDS), which includes discharge data for a stratified sample of 950 U.S. hospital-based EDs located in 30 states. ED visits that resulted in hospitalizations were excluded. Records were included if they indicated a live discharge, an injury diagnosis in any of the first three diagnosis fields, and an external cause of injury (E-code) of falls. When an E-code was missing, it was imputed using information from cases with the same diagnosis and sex. For example, if $95 \%$ of hip fracture diagnoses in women over 65 (after weighting) had an E-code for falls then we imputed a falls E-code among $95 \%$ of the women over 65 who had no E-code listed. We used 2012 data because it was the most recent data available for both ED visits and hospitalizations at the time of analysis.

For office or outpatient visits, we used the Medical Expenditure Panel Survey (MEPS). MEPS is a nationally representative survey of approximately 25,000 non-institutionalized persons that can describe the use of health services among the U.S. population. The external cause of an injury (e.g., fall, fire, poison) was not included in MEPS after 2007. To address this issue, we followed the method described by Englander (Englander et al., 1996). We assumed that the rate in which older adults sought medical care and from whom they received their medical care (e.g., an ED, or medical office) had not changed over time. Therefore we took the proportions of older adults treated in office and outpatient settings in 2007 and applied it to the 2012 census data (https://www.census.gov/population/age/data/ 2012.html). This gave us a 2012 estimate of patients who sought medical care for a fall in an office or outpatient setting by sex and age group (Englander et al., 1996). Outpatient and 
office visits for an injury that also required an ED visit or hospitalization were excluded based on work by Finkelstein (Finkelstein, Corso, \& TR, 2006).

Costs were calculated using claims data from 1998 and 1999 Medicare fee-for-service 5\% Standard Analytical Files and reported previously by Finkelstein et al (Finkelstein et al., 2005). Costs included payment information for all covered services for hospital inpatient, outpatient, skilled nursing, home health, hospice, physicians/supplier services, and durable medical equipment. This dataset, while old, includes out-patient and doctor's office visits and allows us to estimate the cost of falls at multiple treatment sites and capture the cost of a medically treated fall regardless of severity.

We adjusted the non-fatal medical costs for inflation using the 2012 health care component of the PCE price index (McCully et al., 2007). All non-fatal medical costs were computed for total costs and costs stratified by treatment setting, sex, and age group. We produced 2015 estimates of direct and total costs of non-fatal falls by then inflating 2012 costs using the 2015 health care component of the PCE index.

\section{Results}

\subsection{Fatal falls}

In 2012,24,190 adults aged 65 and older died from an unintentional fall. (Table 1) More women died from a fall compared to men $(13,239$ and 10,951) but the incidence of fallrelated death increased with age among both sexes. One-third of all fall-related deaths occurred in women aged 85 and older.

On average, a fatal fall cost $\$ 25,487$. When comparing between men and women, the average cost of a fall death was slightly higher for women. Among age groups, the average cost declined for those 85 and older. However, because of the higher incidence of fall-related death among women 85 and older the total medical costs were higher for these women. Women aged 85 and older accrued one-third of total costs. For men and women combined, fatal falls were an estimated $\$ 616.5$ million in direct medical costs.

\subsection{Non-fatal falls}

Table 2 shows the non-fatal incidence and costs of falls by treatment setting, sex, and age group. In 2012, there were an estimated 3.2 million non-fatal fall injuries; over half (1.76 million falls) were treated in EDs. The total cost of non-fatal falls was $\$ 30.3$ billion and hospitalizations accounted for $57 \%$ ( $\$ 17.2$ billion) of the total costs. The average cost of a non-fatal fall was $\$ 9463$. The average cost of a hospitalization, ED visit, and an office-based or outpatient visit was $\$ 29,562, \$ 4673$, and $\$ 5625$, respectively.

Men experienced 1.07 million falls for a total cost of $\$ 8.8$ billion. The average cost of a medically treated fall increased with age. Hospitalizations cost $\$ 4.9$ billion, more than two and a half times the costs for ED ( $\$ 2.1$ billion) or outpatient treatment ( $\$ 1.8$ billion). 
Women had 2.13 million falls for a total cost of $\$ 21.5$ billion. This included $\$ 12.3$ billion for hospitalizations, $\$ 6.2$ billion for ED visits, and $\$ 3.0$ billion for office-based or outpatient visits. Total and average costs increased with age across all treatment settings.

Overall, women experienced two times the number of medically treated falls compared to men ( 2.13 vs. 1.07 million falls). The total ED cost was almost three times higher for women ( $\$ 6.2$ billion) compared to men ( $\$ 2.1$ billion). Outpatient costs were also higher in women due to a larger incidence of falls treated in outpatient settings. Women accounted for $71 \%$ of the total medical costs for falls ( $\$ 21.5$ out of $\$ 30.3$ billion) and women aged 85 and older were responsible for one-third of the total medical costs ( $\$ 10.1$ out of $\$ 30.3$ billion).

\subsection{Costs in $\mathbf{2 0 1 5}$}

Table 3 shows the direct costs of fatal and non-fatal falls in 2015. Adjusted for inflation, the total cost of a fatal fall in 2015 was $\$ 637.2$ million (\$282.2 million for men, $\$ 355.0$ for women). Non-fatal fall injury treatment cost an estimated $\$ 31.3$ billion ( $\$ 9.0$ billion for men and $\$ 22.2$ billion for women, totals differ due to rounding). The average cost of a medically treated fall rose to $\$ 9780$ (Table 3).

\section{Discussion}

The incidence and costs reported in this analysis differed by treatment setting, sex, and age. Specifically, hospitalized falls were more expensive than falls treated in other settings. Women experienced more medically treated falls and women aged 85 and older comprised $9 \%$ of the older adult population but incurred a third of total hospital related costs.

In the prior analysis by Stevens et al., estimates for direct medical costs of non-fatal falls were $\$ 19$ billion (Stevens et al., 2006). Adjusted for inflation using the health care component of the PCE, direct medical costs for non-fatal falls would be $\$ 27.7$ billion in 2015. We believe our estimate of $\$ 31.3$ billion in 2015 is a more accurate approximation. Although we used previously published calculations of the average costs of falls by treatment setting, sex and age (Finkelstein et al., 2005). we adjusted these costs for both inflation and for changes in the U.S. population structure. Our cost estimates are lower than some previously published numbers (Stevens \& Burns, 2015) because we adjusted for inflation using the PCE to inflate rather than the Consumer Price Index (CPI). The CPI is based on consumer spending and may not completely describe inflation-related medical costs that are paid in large part by the government and private insurance. Given these differences in the inflation factors, we feel our conservative estimates using the PCE are more accurate.

Comparing the cost of falls in different studies is difficult. Sources of data and the cost categories vary. A recent systematic review of nine U.S. studies reported cost estimates that ranged from $\$ 9.3$ to $\$ 29.4$ billion (Davis, Robertson, Ashe, et al., 2010). A 2010 study that included Washington State older adults enrolled in Medicare Advantage reported annual costs of $\$ 35,144$ for hospitalized falls and $\$ 3408$ for non-hospitalized falls (Bohl et al., 2010). Many factors can contribute to these disparities. Differences may be attributed to improved identification of fall injuries treated in hospitals and EDs overtime (Kharrazi, 
Nash, \& Mielenz, 2015). Some studies include only hospital and ED costs (Roudsari et al., 2005). others add costs for treatment in outpatient settings (Carroll et al., 2005; Stevens et al., 2006), or include additional administration and long-term follow-up costs (Finkelstein et al., 2006). Other studies include nursing home residents who fall more frequently and incur higher costs than community-dwelling older adults (Davis et al., 2010).

This study has a number of limitations. First, our non-fatal cost estimates were created using data from 1998-1999 and while they were adjusted for inflation and changes in the incidence of medically treated falls, they may not have accounted for larger changes in health care costs over the same period. Underlying factors such as legislative actions (e.g. the addition of Medicare Part D and the Benefits Improvement and Protection Act), new technology, and an increase in other chronic conditions among older adults, may have changed the cost of falls to Medicare in ways unaccounted for by inflation (Goetghebeur, Forrest, \& Hay, 2003). However, in the absence of more recent cost data to describe the cost burden of falls by treatment location, these data provide an important estimate on the growing burden falls have on medical spending in the United States.

Secondly, our estimates do not address indirect costs of medically treated falls. These include wages lost by both the injured person and their caregiver, as well as non-medical expenditures such as home modifications. Additionally, we do not have data on changes in quality of life or long term functional abilities that also may incur indirect costs.

Healthcare expenditures reached \$3.0 trillion in 2014 and Medicare expenditures represent $20 \%$ of these costs ( $\$ 618.7$ billion) (Centers for Medicare and Medicaid Services, 2014). Injuries/poisonings are the eighth costliest cause of healthcare expenditures (Dunn, Rittmueller, \& Whitmire, 2016) and fall injuries in older adults constitute a large portion of the costs. Cancer, a constellation of diseases, cost Medicare $\$ 36.2$ billion in 2015 (Stockdale et al., 2013) (2011 costs inflated with PCE). Fall related injuries, in contrast, cost $\$ 31.3$ billion. Both categories include a diverse range of conditions that vary in cost and intervention but represent a larger share of expenditures than a single condition such as pneumonia (Pfuntner, Wier, \& Steiner, 2006).

\section{Conclusion}

Each day an estimated 10,000 older Americans turn 65 and become eligible for Medicare. As they age, their risk of falling increases as does their associated medical costs. Thankfully, interventions exist that, when implemented, can reduce the risk of a fall. For example, in 2012, the CDC developed the STEADI (Stopping Elderly Accidents Deaths and Injury) initiative (Summary of the Updated American Geriatrics Society/British Geriatrics Society clinical practice guideline for prevention of falls in older persons, 2011) STEADI is based on the American Geriatric Society and British Geriatric Society published guidelines to promote clinical fall risk assessment and follow-up (Summary of the Updated American Geriatrics Society/British Geriatrics Society clinical practice guideline for prevention of falls in older persons, 2011). Included is information on how to screen for fall risk and conduct effective clinical fall interventions such as optimizing a patient's medications to reduce fall risk, (Boyle, Naganathan, \& Cumming, 2010) and recommending vitamin D supplements 
(Kalyani, Stein, Valiyil, et al., 2010; Moyer, 2012). Both can decrease the incidence of fall injuries and reduce health care costs (Houry, Florence, Baldwin, et al., 2016).

\section{Biographies}

Elizabeth Burns, MPH

Elizabeth Burns is a health scientist within the Division of Unintentional Injury Prevention at the Centers for Disease Control and Prevention. She received her Master of Public Health from Emory University with a concentration in epidemiology and her Bachelor of Science in molecular, cell and development biology from the University of California Santa Cruz. Ms. Burns supports research determining the effectiveness of clinical falls prevention.

Judy Stevens, PhD

Dr.Judy Stevens received her doctorate from Emory University and joined the Injury Centerat CDC in 1996 as an epidemiologist in the Division of Unintentional Injury Prevention. She is a nationally recognized expert on older adult falls and fall prevention. Dr. Stevens has published over eighty peer-reviewed journal articles and has contributed chapters to six textbooks. She also has developed resources for healthcare providers and educational materials for older adults and their caregivers. Dr. Stevens retired from federal service in 2015 but continues to work part-time on fall prevention at the Injury Center as a contractor with Atlanta Technologies Logistics.

\section{Robin Lee, PhD, MPH}

Dr. Robin Lee is the Team Lead for the Home and Recreational Injury Prevention within the Division of Unintentional Injury Prevention at the Centers for Disease Control and Prevention. Dr. Lee and her team conduct research and implement programs on how to prevent the occurrence of unintentional injuries at home, school, and in recreational areas. Dr. Lee received her Master of Public Health and her doctorate in epidemiology from the State University of New York at Albany. She has authored and coauthored numerous presentations and scientific publications and has received awards for her public health and volunteer service.

\section{References}

Alexander BH, Rivara FP, \& Wolf ME (1992). The cost and frequency of hospitalization for fallrelated injuries in older adults. American Journal of Public Health, 82(7),1020-1023. [PubMed: 1609903]

Bohl AA, Fishman PA, Ciol MA, et al. (2010). A longitudinal analysis of total 3-year healthcare costs for older adults who experience a fall requiring medical care. Journal of the American Geriatrics Society, 58(5), 853-860. [PubMed: 20406310]

Boyle N, Naganathan V, \& Cumming RG (2010). Medication and falls: Risk and optimization. Clinics in Geriatric Medicine, 26(4), 583-605. [PubMed: 20934612]

Carroll NV, Slattum PW, \& Cox FM (2005). The cost of falls among the community-dwelling elderly. Journal of Managed Care Pharmacy, 11 (4), 307-316. [PubMed: 15871641]

Centers for Disease Control and Prevention (2005). Web-based injury statistics query and reporting system (WISQARS). National Center for Injury Prevention and Control, Centers for Disease 
Control and Prevention. (Available at http://www.cdc.gov/injury/wisqars/index.html (accessed November 2015).

Centers for Medicare and Medicaid Services (2014). National health expenditures 2014 highlights. Centers for Medicaid and Medicare (Available at https://www.cms.gov/Research-Statistics-Dataand-Systems/Statistics-Trends-and-Reports/NationalHealthExpendData/Downloads/highlights.pdf (accesed January 2016)).

Davis JC, Robertson MC, Ashe MC, et al. (2010). International comparison of cost of falls in older adults living in the community: A systematic review. Osteoporosis international: A journal established as result of cooperation between the European Foundation for Osteoporosis and the National Osteoporosis Foundation of the USA, 21(8), 1295-1306.

Dunn A, Rittmueller L, \& Whitmire B (2016). Health care spending slowdown from 2000 to 2010 was driven by lower growth in cost per case, according to a new data source. Health affairs (Project Hope), 35(1), 132-140. [PubMed: 26733711]

Ellis AA, \& Trent RB (2001). Do the risks and consequences of hospitalized fall injuries among older adults in California vary by type of fall? The Journals of Gerontology. Series A, Biological Sciences and Medical Sciences, 56(11), M686-M692.

Englander F, Hodson TJ, \& Terregrossa RA (1996). Economic dimensions of slip and fall injuries. Journal of Forensic Sciences, 41(5), 733-746. [PubMed: 8789837]

Finkelstein EA, Chen H, Miller TR, et al. (2005). A comparison of the case-control and case-crossover designs for estimating medical costs of nonfatal fall-related injuries among older Americans. Medical Care, 43(11), 1087-1091. [PubMed: 16224301]

Finkelstein EA, Corso PS, \& TR M (2006). The incidence and economic burden of injuries in the United States. Oxford University Press.

Goetghebeur MM, Forrest S, \& Hay JW (2003). Understanding the underlying drivers of inpatient cost growth: A literature review. The American Journal of Managed Care, 9(Spec No 1), SP3-SP12. [PubMed: 12817611]

Hodgson TA, \& Cohen AJ (1999). Medical expenditures for major diseases, 1995. Health Care Financing Review, 21(2), 119-164. [PubMed: 11481772]

Hornbrook MC, Stevens VJ, Wingfield DJ, et al. (1994). Preventing falls among community-dwelling older persons: Results from a randomized trial. The Gerontologist, 34(1), 16-23. [PubMed: 8150304]

Houry D, Florence C, Baldwin G, et al. (2016). The CDC Injury Center's response to the growing public health problem of falls among older adults. American Journal of Lifestyle Medicine, 10(1).

Kalyani RR, Stein B, Valiyil R, et al. (2010). Vitamin D treatment for the prevention of falls in older adults: Systematic review and meta-analysis. Journal of the American Geriatrics Society, 58(7), 1299-1310. [PubMed: 20579169]

Kharrazi RJ, Nash D, \& Mielenz TJ (2015). Increasing trend of fatal falls in older adults in the United States, 1992 to 2005: Coding practice or reporting quality? Journal of the American Geriatrics Society, 63(9), 1913-1917. [PubMed: 26200220]

Lawrence B, \& Miller T (2014). Medical and work-loss cost estimation methods for the WISQARS cost of injury module. Available at http://www.pire.org/documents/WisqarsCostMethods.pdf (accessed November 2015)

Mahoney JE, Glysch RL, Guilfoyle SM, et al. (2005). Trends, risk factors, and prevention of falls in older adults in Wisconsin. WMJ: Official publication of the State Medical Society of Wisconsin, 104(1),22-28.

McCully CP, Moyer BC, \& Stewart KJ (2007). Comparing the consumer price index and the personal consumption expenditures price index. Survey of Current Business, 87(11), 26-33.

Moyer VA (2012). Prevention of falls in community-dwelling older adults: U.S. Preventive services task force recommendation statement. Annals of Internal Medicine, 157(3), 197-204. [PubMed: 22868837]

Pfuntner A, Wier LM, \& Steiner C (2006). Costs for hospital stays in the United States, 2011: Statistical brief \#168 Healthcare cost and utilization project (HCUP) statistical briefs. Rockville (MD): Agency for Health Care Policy and Research (US). 
Rizzo JA, Friedkin R, Williams CS, et al. (1998). Health care utilization and costs in a Medicare population by fall status. Medical Care, 36(8), 1174-1188. [PubMed: 9708590]

Roudsari BS, Ebel BE, Corso PS, et al. (2005). The acute medical care costs of fall-related injuries among the U.S. older adults. Injury, 36(11), 1316-1322. [PubMed: 16214476]

Shumway-Cook A, Ciol MA, Hoffman J, et al. (2009). Falls in the Medicare population: Incidence, associated factors, and impact on health care. Physical Therapy, 89(4), 324-332. [PubMed: 19228831]

Stevens JA, \& Burns ER (2015). A CDC compendium of effective fall interventions: What works for community-dwelling older adults (3rd ed.). Atlanta, GA: Centers for Disease Control and Prevention, National Center for Injury Prevention and Control.

Stevens JA, Corso PS, Finkelstein EA, et al. (2006). The costs of fatal and non-fatal falls among older adults. Injury prevention: Journal of the International Society for Child and Adolescent Injury Prevention, 12(5), 290-295. [PubMed: 17018668]

Stockdale H, \& Guillory K (2013). In American Cancer Society Cancer Action Network (Ed.), Why cancer patients depend on medicare for critical coverage (Available at http://www.acscan.org/ content/wp-content/uploads/2013/06/2013-Medicare-Chartbook-Online-Version.pdf (accessed January 2016)).

Summary of the Updated American Geriatrics Society/British Geriatrics Society clinical practice guideline for prevention of falls in older persons (2011h). Journal of the American Geriatrics Society, 59(1), 148-157. [PubMed: 21226685]

Wiener JM, \& Tilly J (2002). Population ageing in the United States of America: Implications for public programmes. International Journal of Epidemiology, 31(4), 776-781. [PubMed: 12177018]

J Safety Res. Author manuscript; available in PMC 2019 November 01. 


\section{What is already known on the subject?}

- $\quad$ Falls are the leading cause of both fatal and non-fatal injuries among people aged 65 and older.

- In 2000, the direct medical costs of falls were estimated to be $\$ 179$ million for fatal falls and $\$ 19$ billion for non-fatal falls. 


\section{What this study adds?}

- In 2015, the direct medical costs of falls are $\$ 637.2$ million for fatal falls and $\$ 31.3$ billion for non-fatal falls.

- In 2015 , the average cost of a fatal fall was $\$ 26,340$ while the average cost of a nonfatal fall was $\$ 9780$. 


\section{Table 1}

Fatal fall injuries: Incidence and costs by sex and age, United States, 2012.

\begin{tabular}{|c|c|c|c|c|c|}
\hline & Incidence & Incidence (\%) & Av. cost per fall & Total cost ${ }^{a}$ & Cost $(\%)$ \\
\hline Total & 24,190 & & $\$ 25,487$ & $\$ 616.5$ & \\
\hline \multicolumn{6}{|l|}{ Sex } \\
\hline Men & 10,951 & 45.3 & $\$ 24,935$ & $\$ 273.1$ & 44.3 \\
\hline \multicolumn{6}{|l|}{ Age } \\
\hline $65-74$ & 1996 & 18.2 & $\$ 25,145$ & $\$ 50.2$ & 18.5 \\
\hline $75-84$ & 3912 & 35.7 & $\$ 26,324$ & $\$ 103.0$ & 37.7 \\
\hline $85+$ & 5043 & 46.1 & $\$ 23,684$ & $\$ 119.4$ & 43.8 \\
\hline Women & 13,239 & 54.7 & $\$ 25,944$ & $\$ 343.5$ & 55.7 \\
\hline \multicolumn{6}{|l|}{ Age } \\
\hline $65-74$ & 1336 & 10.1 & $\$ 26,774$ & $\$ 35.8$ & 10.4 \\
\hline $75-84$ & 3864 & 29.2 & $\$ 26,950$ & $\$ 104.1$ & 30.3 \\
\hline $85+$ & 8039 & 60.7 & $\$ 25,290$ & $\$ 203.3$ & 59.2 \\
\hline
\end{tabular}

${ }^{a}$ In millions. Totals may differ because of rounding. 


\section{Table 2}

Non-fatal fall injuries: Incidence and costs by treatment setting sex, and age, United States, 2012.

\begin{tabular}{|c|c|c|c|c|c|c|c|c|c|c|c|c|}
\hline & \multicolumn{3}{|l|}{$\underline{\text { Total }}$} & \multicolumn{3}{|c|}{$\underline{\text { Hospitalizations }}$} & \multicolumn{3}{|l|}{ ED visits } & \multicolumn{3}{|c|}{$\begin{array}{l}\text { Office based and outpatient } \\
\text { visits }\end{array}$} \\
\hline & Incidence & $\begin{array}{l}\text { Av. cost } \\
\text { per fall }\end{array}$ & $\begin{array}{l}\text { Total } \\
\operatorname{cost}^{a}\end{array}$ & Incidence & $\begin{array}{l}\text { Av. cost } \\
\text { per fall }\end{array}$ & $\begin{array}{l}\text { Total } \\
\operatorname{cost}^{a}\end{array}$ & Incidence & $\begin{array}{l}\text { Av. } \\
\text { cost } \\
\text { per } \\
\text { fall }\end{array}$ & $\begin{array}{l}\text { Total } \\
\text { cost }^{a}\end{array}$ & Incidence & $\begin{array}{l}\text { Av. } \\
\text { cost } \\
\text { per } \\
\text { fall }\end{array}$ & $\begin{array}{l}\text { Total } \\
\text { cost }\end{array}$ \\
\hline Total & $3,200,152$ & $\$ 9463$ & $\$ 30.3$ & 583,036 & $\$ 29,562$ & $\$ 17.2$ & $1,757,913$ & $\$ 4673$ & $\$ 8.2$ & 859,203 & $\$ 5625$ & $\$ 4.8$ \\
\hline \multicolumn{13}{|l|}{ Sex } \\
\hline Men & $1,069,193$ & $\$ 8188$ & $\$ 8.8$ & 171,900 & $\$ 28,455$ & $\$ 4.9$ & 547,329 & $\$ 3768$ & $\$ 2.1$ & 349,964 & $\$ 5145$ & $\$ 1.8$ \\
\hline \multicolumn{13}{|l|}{ Age } \\
\hline $65-74$ & 419,237 & $\$ 5778$ & $\$ 2.4$ & 49,823 & $\$ 26,643$ & $\$ 1.3$ & 194,889 & $\$ 2219$ & $\$ 0.4$ & 174,525 & $\$ 3796$ & $\$ 0.7$ \\
\hline $75-84$ & 377,530 & $\$ 9352$ & $\$ 3.5$ & 65,182 & $\$ 29,470$ & $\$ 1.9$ & 202,288 & $\$ 4792$ & $\$ 1.0$ & 110,060 & $\$ 5818$ & $\$ 0.6$ \\
\hline $85+$ & 272,426 & $\$ 10,283$ & $\$ 2.8$ & 56,895 & $\$ 28,878$ & $\$ 1.6$ & 150,152 & $\$ 4400$ & $\$ 0.7$ & 65,379 & $\$ 7612$ & $\$ 0.5$ \\
\hline Women & $2,130,959$ & $\$ 10,103$ & $\$ 21.5$ & 411,136 & $\$ 30,024$ & $\$ 12.3$ & $1,210,584$ & $\$ 5082$ & $\$ 6.2$ & 509,239 & $\$ 5956$ & $\$ 3.0$ \\
\hline \multicolumn{13}{|l|}{ Age } \\
\hline $65-74$ & 636,835 & $\$ 6478$ & $\$ 4.1$ & 84,428 & $\$ 26,073$ & $\$ 2.2$ & 390,388 & $\$ 3224$ & $\$ 1.3$ & 162,019 & $\$ 4109$ & $\$ 0.7$ \\
\hline $75-84$ & 748,018 & $\$ 9770$ & $\$ 7.3$ & 149,157 & $\$ 29,857$ & $\$ 4.5$ & 422,316 & $\$ 4143$ & $\$ 1.7$ & 176,545 & $\$ 6258$ & $\$ 1.1$ \\
\hline $85+$ & 746,106 & $\$ 13,531$ & $\$ 10.1$ & 177,551 & $\$ 32,044$ & $\$ 5.7$ & 397,880 & $\$ 7901$ & $\$ 3.1$ & 170,675 & $\$ 7395$ & $\$ 1.3$ \\
\hline
\end{tabular}

In billions. Totals may differ because of rounding. 


\section{Table 3}

2015 inflated fatal and nonfatal cost estimates for unintentional fall injuries by treatment setting and sex, United States, 2015.

\begin{tabular}{|c|c|c|c|c|c|c|c|c|c|c|}
\hline & \multicolumn{2}{|l|}{$\underline{\text { Fatal }}$} & \multicolumn{2}{|c|}{ Nonfatal total } & \multicolumn{2}{|c|}{ Hospitalizations } & \multicolumn{2}{|l|}{$\underline{\text { ED visits }}$} & \multicolumn{2}{|c|}{$\begin{array}{l}\text { Office based and } \\
\text { outpatient visits }\end{array}$} \\
\hline & $\begin{array}{l}\text { Av. cost } \\
\text { per fall }\end{array}$ & $\begin{array}{l}\text { Total } \\
\text { cost }{ }^{a}\end{array}$ & $\begin{array}{l}\text { Av. cost } \\
\text { per fall }\end{array}$ & $\begin{array}{l}\text { Total } \\
\text { cost } b\end{array}$ & $\begin{array}{l}\text { Av. cost } \\
\text { per fall }\end{array}$ & $\begin{array}{l}\text { Total } \\
\text { cost }\end{array}$ & $\begin{array}{l}\text { Av. cost } \\
\text { per fall }\end{array}$ & $\begin{array}{l}\text { Total } \\
\text { cost } b\end{array}$ & $\begin{array}{l}\text { Av. cost } \\
\text { per fall }\end{array}$ & $\begin{array}{l}\text { Total } \\
\text { cost } b\end{array}$ \\
\hline Total & $\$ 26,340$ & $\$ 637.2$ & $\$ 9780$ & $\$ 31.3$ & $\$ 30,550$ & $\$ 17.8$ & $\$ 4829$ & $\$ 8.5$ & $\$ 5813$ & $\$ 5.0$ \\
\hline \multicolumn{11}{|l|}{ Sex } \\
\hline Men & $\$ 25,769$ & $\$ 282.2$ & $\$ 8462$ & $\$ 9.0$ & $\$ 29,407$ & $\$ 5.1$ & $\$ 3894$ & $\$ 2.1$ & $\$ 5317$ & $\$ 1.9$ \\
\hline Women & $\$ 26,812$ & $\$ 355.0$ & $\$ 10,441$ & $\$ 22.2$ & $\$ 31,029$ & $\$ 12.8$ & $\$ 5252$ & $\$ 6.4$ & $\$ 6155$ & $\$ 3.1$ \\
\hline
\end{tabular}

Totals may differ because of rounding. All costs are inflated but not adjusted for changes in incidence between 2012 and 2015 .

${ }^{a}$ In millions.

$b_{\text {In billions. }}$ 